\title{
Oldham nurses benefit from bursary
}

Three student dental nurses are the first to benefit from a training bursary launched by health chiefs in memory of a dedicated Oldham dental nurse who died last year.

The Naveed Maqsood Training Bursary was launched after the tragic death of the 23-yearold from cancer in June last year.

Naveed had spent two years on the PCT's bilingual dental nurse training programme before joining John Scott's dental practice in Leeds.

Now student dental nurses Bushra Ibrar, 31, Rohima Khatun, 21 and 20-year-old Joohora Begum will all have the chance to take part in extra training to improve their skills - and help their patients.

'The dentists need nurses who have a range of skills' says Rohima. 'Thanks to the bursary, I'll be able to assist the dentist with sedation and because I'm bilingual I can also explain to Bengali patients what we are doing and why'

\section{CoDTEI}

The newly formed Conference of Dental Technology Educational Institutes (CoDTEI) held its first meeting recently in London. The group comprises dental technology teaching staff, managers and directors who are also registered dental technicians in participating educational institutes in the UK.

During the conference a range of topics were aired from consideration of the wider EU perspective to the business meeting rules. Antony Townsend, Registrar of the GDC, provided delegates with an up to date overview of the progress towards the statutory registration.

The Chief Dental Officer for England, Professor Raman Bedi, also formally congratulated them for taking the conference

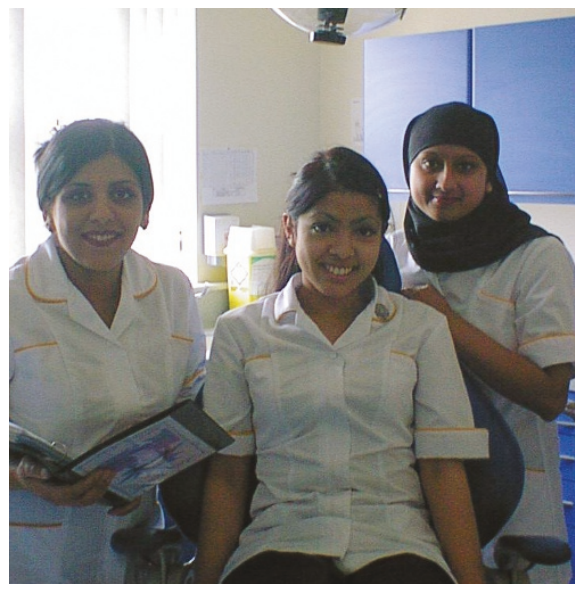

From left: Bushra Ibrar, Rohima Khatun in the dentist's chair, and Joohora Begum

The bursary is open to any bilingual PCT employee, not just dentistry staff and will provide $£ 1,000$ annually, which can be used to pay for anything from training courses to books.

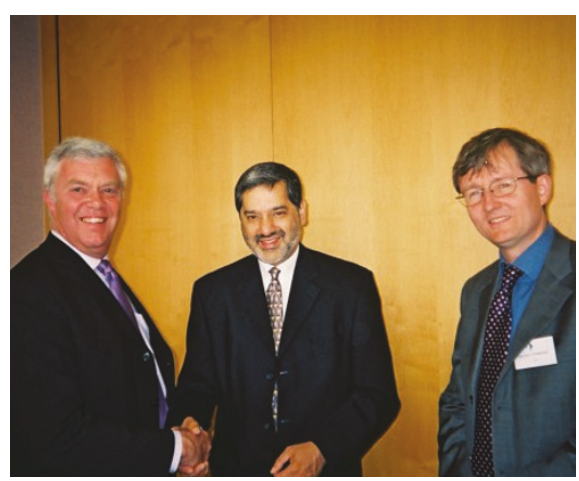

forward to develop closer liaison and improving the provision of dental technology training for the registrable qualifications within the UK.

Pictured from left to right: Tony Griffin, Manager of the School of Dental Nursing and Dental Technology, Chief Dental Officer, Raman Bedi and Antony Townsend, Registrar of the GDC.

\section{Orthodontic nurse award}

The Orthodontic National Group is inviting entries for the Orthodontic Dental Nurse Award 2004, which is now in its ninth year. Nurses can enter by sending a short synopsis on a subject relevant to orthodontics to the judges, and out of these entries five finalists will be selected. They are then to give a 10 minute presentation at the British Orthodontic Conference in September before the winner is chosen. The winner will also be invited to present at a similar competition at the 6th International Orthodontic Congress in Paris in 2005. The award was set up to encourage and develop the knowledge and skills in this area, and winners receive a prize of $£ 300$ as well as the award. 